\title{
Facing metal stress by multiple strategies: morphophysiological responses of cardoon (Cynara cardunculus L.) grown in hydroponics
}

\author{
Maria Cristina Sorrentino ${ }^{1} \cdot$ Fiore Capozzi $^{1} \cdot$ Chiara Amitrano $^{2} \cdot$ Gaetano De Tommaso $^{3} \cdot$ Carmen Arena $^{1}$. \\ Mauro Iuliano $^{3} \cdot$ Simonetta Giordano $^{1} \cdot$ Valeria Spagnuolo $^{1}$
}

Received: 14 December 2020 / Accepted: 26 February 2021 / Published online: 14 March 2021

(C) The Author(s) 2021

\begin{abstract}
The contamination of environments by heavy metals has become an urgent issue causing undesirable accumulations and severe damages to agricultural crops, especially cadmium and lead which are among the most widespread and dangerous metal pollutants worldwide. The selection of proper species is a crucial step in many plant-based restoration approaches; therefore, the aim of the present work was to check for early morphophysiological responsive traits in three cultivars of Cynara cardunculus (Sardo, Siciliano, and Spagnolo), helping to select the best performing cultivar for phytoremediation. For all three tested cultivars, our results indicate that cardoon displays some morphophysiological traits to face $\mathrm{Cd}$ and $\mathrm{Pb}$ pollution, particularly at the root morphology level, element uptake ability, and photosynthetic pigment content. Other traits show instead a cultivar-specific behavior; in fact, stomata plasticity, photosynthetic pattern, and antioxidant power provide different responses, but only Spagnolo cv. achieves a successful strategy attaining a real resilience to metal stress. The capacity of Spagnolo plants to modify leaf structural and physiological traits under heavy metal contamination to maintain high photosynthetic efficiency should be considered an elective trait for its use in contaminated environments.
\end{abstract}

Keywords Cardoon $\cdot$ Stomata $\cdot$ Root hairs $\cdot$ Gas exchanges $\cdot$ Cadmium $\cdot$ Lead

\section{Introduction}

Rapid urbanization and agricultural practices can be considered the main responsible for metal pollution of land, water, and plants, with a generally detrimental effect for all living organisms. Although heavy metals are natural components of soil at trace levels, and some of them (i.e., $\mathrm{Cu}$ and $\mathrm{Zn}$ ) are

Responsible Editor: Gangrong Shi

Carmen Arena

carmen.arena@unina.it

$\triangle$ Valeria Spagnuolo

valeria.spagnuolo@unina.it

1 Dipartimento di Biologia, Università degli Studi di Napoli Federico II, Complesso Universitario di Monte Sant'Angelo, Cupa Nuova Cintia, 21-80126 Napoli, Italy

2 Dipartimento di Agraria, Università degli Studi di Napoli Federico II, Via Università, 100-80055 Portici, Italy

3 Dipartimento di Scienze Chimiche, Università degli Studi di Napoli Federico II, Complesso Universitario di Monte Sant'Angelo, Cupa Nuova Cintia, 21-80126 Napoli, Italy essential for normal plant growth and development, the increasing anthropogenic activities have contributed to their accumulations. Urbanization involves industrialization and massive vehicular traffic, which release pollutants to air, soil, and water. Moreover, farmland activities sometimes imply the use of contaminated irrigation water, and mineral fertilizers, herbicides, and additives for animal feeds, with a global increase in metal pollution. As a consequence of current land-use practices, or activities inducing heavy metal mobilization, many soils are contaminated by these pollutants, especially in the form of pesticides and nutrients (Motuzova et al. 2014). In recent time, soil contamination by heavy metals has become an urgent issue, since it results in a severe loss in agricultural yield and damages in human health, due to metal entrance into the food web and biomagnification of some metals, such as $\mathrm{Pb}$ and $\mathrm{Cd}$ (He et al. 2015; Su et al. 2014).

The toxicity of heavy metals on plant metabolism has received extensive interest for several decades (Markert 1993), with particular attention to crops (Chaney 2015), whose contamination can cause health problems, as these plants are directly related to the human diet. Cadmium $(\mathrm{Cd})$ and lead $(\mathrm{Pb})$ are among the most widespread metal pollutants worldwide 
(Su et al. 2014). Pb naturally occurs in soils, but it is present in relatively low concentrations. In uncontaminated soils, $\mathrm{Pb}$ is generally in the range of $20-50 \mathrm{mg} \mathrm{kg}^{-1}$ (Nriagu 1978). Nonpolluted soils usually contain less than $100 \mathrm{mg} \mathrm{kg}^{-1} \mathrm{~Pb}$; soils in unpolluted polar areas, buried before the industrial revolution, contain less than $5 \mathrm{mg} \mathrm{kg}^{-1}$ (Meggeson and Hall 1999). In industrialized areas, up to $1000 \mathrm{mg} \mathrm{kg}^{-1} \mathrm{~Pb}$ and above has been recorded (Angelone and Bini 1992; Capozzi et al. 2020). In recent studies carried out in Southern Italy, aimed at the environmental restoration of metalcontaminated areas, some industrial sites were selected, with $\mathrm{Cd}$ and $\mathrm{Pb}$ concentrations ranging between 1.6 and $314 \mathrm{mg}$ $\mathrm{kg}^{-1}$, and 409 and $100,000 \mathrm{mg} \mathrm{kg}^{-1}$, respectively (Capozzi et al. 2020; Visconti et al. 2018).

Cadmium naturally occurs in $\mathrm{Zn}, \mathrm{Pb}$, and $\mathrm{Cu}$ ores with $\mathrm{Zn}$ concentration exceeding 50-200-folds $\mathrm{Cd}$; the mining and smelting of these ores involve $\mathrm{Cd}$ contamination of surrounding soils (Chaney 2015).

In plants, the exposition to heavy metals, and especially $\mathrm{Cd}$, results in a severe reduction of plant growth and development as a consequence of photosynthetic apparatus impairment (Arena et al. 2014). Photosynthesis is one of the processes sensitive to metal toxicity (Arena et al. 2017a, b; Figlioli et al. 2019; Krupa and Baszyński 1995; Sorrentino et al. 2018). Metals may have multidirectional effects on photosynthesis (for a review see Prasad and Strzalka 1999). The excess of Cd or $\mathrm{Pb}$, for example, affects the photosynthetic electron transport (Krupa and Baszyński 1995; Myśliwa-Kurdziel et al. 2002), as well as the activities of Calvin-Benson cycle enzymes, or the net assimilation of $\mathrm{CO}_{2}$ (Arena et al. 2017a, b; Prasad and Strzalka 1999; Sorrentino et al. 2018). Photosynthetic activity can also be altered indirectly by heavy metals, for example, decreasing the content of photosynthetic pigments, altering chloroplast ultrastructure (Molas 2002; Sorrentino et al. 2018), and lipid and protein composition of thylakoids (Skórzyńska-Polit and Baszyński 1997). Cadmium and Pb accumulation in leaves interferes with the stomata functioning, affecting the overall photosynthesis and transpiration rates (Chandra and Kang 2016). The plant physiological response against heavy metals is strictly depending on the species, being linked to the plant individual capability to face stress. Some species are powerful bioaccumulators (Arena et al. 2017a, b) and used in phytoremediation of contaminated soils.

In previous works (Capozzi et al. 2020; Sorrentino et al. 2018) carried out on Cynara cardunculus L. var. altilis DC., three cultivars were grown on a gardening soil and on industrial soil containing $\mathrm{Cd}$ and $\mathrm{Pb}$, and different behaviors were observed under metal stress compared to the control plants. Although all cultivars could uptake significant amounts of metals, only C. cardunculus cv Spagnolo counteracted metal stress preserving chloroplast ultrastructure and increasing photosynthetic efficacy. By contrast, in the other cultivars analyzed, $\mathrm{Cd}$ and $\mathrm{Pb}$ uptake was coupled to the decrease in life span, pigment content, and photosynthetic activity. The selection of a species for phytoremediation of metal-polluted soils involves a deep knowledge of the mechanisms at the basis of plant resistance against metal stress; based on previous experimental evidences, C. cardunculus, cv Spagnolo, seems to be an eligible candidate for phytoremediation. We hypothesized that $\mathrm{Cd}$ and $\mathrm{Pb}$, provided in hydroponic cultures, could affect other morphophysiological traits, useful as an early proxy of metal stress in the selection of phytoremediation species. Therefore, the aim of the present work was to verify if cultivar-specific responses occurred, considering (i) the number of stomata and the total stomata surface in relation to gas exchanges, (ii) root morphology in relation to metal uptake and translocation, and (iii) pigment content, photochemical efficiency, and antioxidant response.

\section{Materials and methods}

\section{Plant material and growth conditions}

The seeds of three cultivars of Cynara cardunculus var. altilis DC. (provided by Arca 2010 scarl), named Sardo (SAR), Siciliano (SIC), and Spagnolo (SPA), were germinated on wet filter paper for five days in the dark. Once primary roots and cotyledons were fully developed, 15 seedlings of each cultivar were moved to a hydroponic floating system, consisting of polystyrene plug trays floating in plastic tanks containing a constant volume of $5 \mathrm{~L}$ of aerated nutrient solution (Hoagland and Arnon 1950) at pH 5.5. Three tanks were used for the experimental plan: 5 seedlings of each cultivar per tank were exposed to a specific heavy metal or none as the control; at the two-true-leaf stage, $\mathrm{CdCl}_{2}$ and $\mathrm{Pb}\left(\mathrm{NO}_{3}\right)_{2}$ at the concentration of $10^{-5} \mathrm{M}$ were supplied to the culture medium. The nutrient solution was renewed twice a week for $30 \mathrm{~d}$. The parameters of the growth chamber were constantly monitored to maintain controlled conditions of temperature $24 / 18{ }^{\circ} \mathrm{C}$, relative humidity $(\mathrm{RH}) 55-75 \%$ (day/night), and a photoperiod of $16 \mathrm{~h}$ light per day with a photosynthetic photon flux density (PPFD) at the top of the canopy of 180-200 $\mu \mathrm{mol}$ photons $\mathrm{m}^{-2} \mathrm{~s}^{-1}$. After $30 \mathrm{~d}$ culture, all plants were analyzed.

\section{Morphological traits of roots and stomata}

Root tips (5 for each thesis) from controls and metal-treated plants, at the end of the treatment, were cut under a stereomicroscope and observed under LM (Leica DME ICC50W) to estimate the presence of root hair and the extension of the hair zone. To determine the stomata size and number, four leaves of each cultivar were collected after the heavy metal exposure. All selected leaves were at the same age and development degree. A gentle peeling of the abaxial surface was carried out with scotch tape to remove trichomes. At the midlamina, four surface replicas were obtained by nail topcoat. For each thesis, 16 
replicas were observed under a light microscope $(n=16$, total analyzed surface $=0.8 \mathrm{~mm}^{2} \times 16$ ), and images acquired were analyzed by ImageJ software (National Institutes of Health, MD, USA) (Fig. 1a). Moreover, 20 stomata (i.e., 20 couples of guard cells) were measured for each thesis: both major and minor axes of each stoma were used to calculate its area as an ellipse (Fig. 1b). Then, this area was multiplied per the average stomata number found on a $0.8 \mathrm{~mm}^{2}$ area, and this value was assumed as the total stomata surface (TSS).

\section{Chemical analysis and sequential elution technique}

To evaluate the total amounts of intra- and extracellular fractions of $\mathrm{Cd}$ and $\mathrm{Pb}$, a sequential elution technique was used. Treated samples were divided into two batches: one batch was directly analyzed for the total element content, after dehydration and acid digestion. The second batch was put in $20 \mathrm{~mL}$ of $20 \mathrm{mM} \mathrm{Na}{ }_{2}$ EDTA solution for $20 \mathrm{~min}$ and then rinsed in deionized water, to remove the extracellular soluble fraction of $\mathrm{Cd}$ or $\mathrm{Pb}$, also including that bound to the cell wall (Branquinho and Brown 1994; Branquinho et al. 1997; Spagnuolo et al. 2011). Specifically, all samples (shoot and root for total element content and only shoot for sequential elution; $n=5$ ) were weighted and dried in an oven at $40{ }^{\circ} \mathrm{C}$ until constant weight. Dehydrated plant materials were ground in an agate mortar for the digestion phase. Samples represented by root or leaf powder of weight between 100 and $250 \mathrm{mg}$ were digested in $5 \mathrm{~mL} \mathrm{HNO}_{3} 65 \%$ (hyperpure, Carlo Erba) and $2.5 \mathrm{~mL} \mathrm{H}_{2} \mathrm{O}_{2} 30 \%$ (Sigma Aldrich) for metal analysis.

The digested samples were diluted to $25 \mathrm{~mL}$ in Millipore water and subsequently filtered to analyze $\mathrm{Pb}$ and $\mathrm{Cd}$ by Flame AAS (Varian Spectra AA 220 FS). All Pb and Cd standard solutions, for calibration curves, were prepared in $0.1 \mathrm{M} \mathrm{HNO}_{3}$ by dilution of $\mathrm{Pb}\left(\mathrm{NO}_{3}\right)_{2}$ and $\mathrm{Cd}\left(\mathrm{NO}_{3}\right)_{2}$ stock solutions, respectively. Lead (II) and cadmium (II) nitrate stock solutions were prepared by dissolving lead or cadmium metal, 5N8 (Metal Research) with a nitric acid stock solution. The exact metal concentration, in both solutions, was determined by complexometric titration with EDTA. The reference plant material CTA-OTL-1 (oriental tobacco leaves) was also acid-digested and analyzed for $\mathrm{Cd}$ and $\mathrm{Pb}$ concentrations, to determine the recovery percentages of the two elements; they were 92 and $103 \%$, respectively.

\section{Gas exchange analysis}

For the gas exchange and fluorescence measurements, fully expanded leaves were collected at $30 \mathrm{~d}$ after sowing.
Fig. 1 Example of stomata counting (a) and measuring (b) in a control sample of Spagnolo cardoon. Pb-treated samples of Spagnolo (c) and Siciliano (d) leaf replicas. Note the higher number of smaller stomata in the first; see paragraph 3.1 for further details

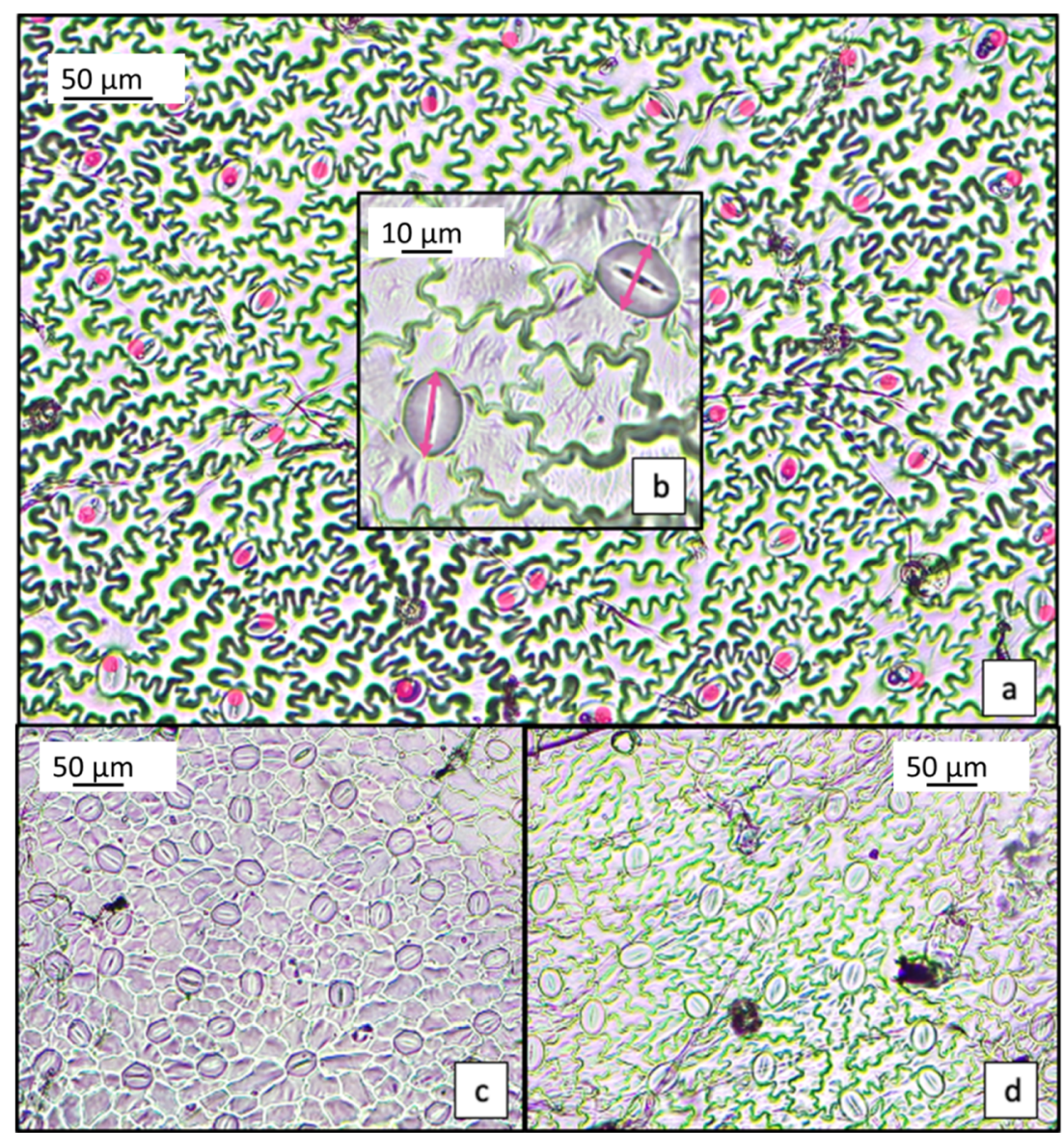


Leaf gas exchanges were measured with a modular gas exchange measuring system equipped with an infrared gas analyzer QUBIT SYSTEMS S151 IRGA $\mathrm{CO}_{2}$ analyzer (Qubit Systems Inc., Kingston, Ontario, Canada) to measure, at different times, the concentration of $\mathrm{CO}_{2}$ in gas entering a leaf chamber, and the concentration of $\mathrm{CO}_{2}$ in the same gas after it leaves the chamber. The difference between influx and efflux $\mathrm{CO}_{2}$ concentrations allowed the calculation of the photosynthetic $\mathrm{CO}_{2}$ fixation rate. The system included a humidity/ temperature sensor (Q-S161) which measured relative humidity of the air before and after it has passed through the leaf chamber plus temperature at the RH sensor. The RH differential between influx and efflux gas, the temperature, and the flow rate through the leaf chamber allowed calculation of leaf transpiration rates.

The youngest full expanded leaves ( 5 leaves per plant for each treatment) were chosen for the measurements. Each leaf was enclosed in the leaf chamber for about 5-8 minutes to allow the photosynthesis to reach the steady state. The environmental parameter fixed in the chamber was photosynthetic photon flux density (PPFD) of $800 \mu \mathrm{mol}$ photons $\mathrm{m}^{-2} \mathrm{~s}^{-1}$, temperature of $25{ }^{\circ} \mathrm{C} \pm 1$, ambient $\mathrm{CO}_{2}$ concentration of $360 \mu \mathrm{mol} \mathrm{CO} 2 \mathrm{~mol}^{-1}$, and RH 50\%. The PPFD on cuvette was provided by a LED external source (A113, Qubit System) which supplies photosynthetically active radiation to the leaf with minimum heat load. Net photosynthesis $\left(A_{N}\right)$, transpiration $(E)$, and stomatal conductance to vapor $\left(g_{s}\right)$ were calculated according to the LoggerPro software (Qubit Systems Inc., Canada) as reported in Sengupta et al. 2019.

Using the differential $\mathrm{CO}_{2}$ concentration, which is the difference between the influx and efflux $\mathrm{CO}_{2}$ (dif. $\mathrm{CO}_{2}$ ), following the molecular flow (MF) rate, net-photosynthesis was calculated as follows:

$A_{N}=$ dif. $\mathrm{CO}_{2} \times \mathrm{MF}$ transpiration rate

where MF $=$ flow rate/[22.4 $\times(273+$ Tair $) / 273] / 60 \times 10,000 /$ leaf area.

Transpiration $(E)$ was also calculated automatically by the software by using the values of reference and analytical relative humidity $(\mathrm{RH})$ values. Stomatal conductance was calculated as reported:

$g_{s}=E /($ ws - Anal.w $)$

where ws is the water vapor concentration in saturated air and Anal. $w$ is the analyzed water vapor.

\section{Photosynthetic pigment content}

Total chlorophylls and carotenoids were determined at 30 DAS on the same 5 leaves per treatment utilized for gas exchange and fluorescence emission measurements, according to Lichtenthaler (1987). Pigments were extracted from leaf disks of $0.2 \mathrm{~cm}^{2}$ by mortar and pestle in ice-cold $100 \%$ acetone and centrifuged at $5000 \mathrm{rpm}$ for $5 \mathrm{~min}$ (Labofuge GL, Heraeus Sepatech, Hanau, Germany). The absorbance of supernatants was quantified by a spectrophotometer (Cary 100 UV-VIS, Agilent Technologies, Santa Clara, CA, USA) at 470, 645, and $662 \mathrm{~nm}$ and pigment concentration expressed in $\mu \mathrm{g} \mathrm{cm}^{-1}$.

\section{Fluorescence emission measurements}

Fluorescence emission measurements were also performed on five replicates per each treatment, coming from five different plants. A portable FluorPen FP100max fluorometer, equipped with a light sensor (Photon System Instruments, Brno, Czech), was used for measurements, following the procedure reported in Arena et al. (2017a). The ground fluorescence signal, $F_{o}$, was induced on $30^{\prime}$ dark-adapted leaves, by a blue LED internal light of about $1-2 \mu \mathrm{mol} \mathrm{m} \mathrm{m}^{-2} \mathrm{~s}^{-1}$. The maximal fluorescence level in the dark, $F_{m}$, was induced by a $1 \mathrm{~s}$ saturating light pulse of $3000 \mu \mathrm{mol} \mathrm{m} \mathrm{m}^{-2} \mathrm{~s}^{-1}$. The maximum quantum efficiency of PSII photochemistry, $F_{v} / F_{m}$, was calculated as $\left(F_{m}-F_{o}\right) / F_{m}$, according to Kitajima and Butler (1975). The fluorescence measurements in the light were performed utilizing an open leaf-clip suitable for measurements under ambient light. The quantum yield of PSII electron transport $\left(\Phi_{\text {PSII }}\right)$ was determined according to Genty et al. (1989). The linear electron transport rate (ETR) was expressed following Krall and Edwards (1992), whereas the nonphotochemical quenching (NPQ) was calculated as described in Bilger and Björkman (1990).

\section{Antioxidant capacity determination}

The antioxidant analysis was carried out following the procedure reported in Costanzo et al. 2020, by the ferric reducing antioxidant power assay (FRAP). More specifically, $0.25 \mathrm{~g}$ of powdered sample was mixed with $60: 40(\mathrm{v} / \mathrm{v})$ methanol/water solution and centrifuged at $14000 \mathrm{rpm}$ for $15 \mathrm{~min}$ at $4{ }^{\circ} \mathrm{C}$. Then, an acetate buffer (1:16 $300 \mathrm{mM} \mathrm{pH} \mathrm{3.6)} \mathrm{containing} \mathrm{a}$ mix of tripyridyltriazine (TPTZ) $(1: 1.610 \mathrm{mM}$ TPTZ in $40 \mathrm{mM} \mathrm{HCl})$ and $\mathrm{FeCl}_{3}(1: 1612 \mathrm{mM} \mathrm{FeCl}$ ) was added to the extracts. The absorbance was measured at $593 \mathrm{~nm}$ with a spectrophotometer (UV-VIS Cary 100, Agilent Technologies, Palo Alto, CA, USA) after $1 \mathrm{~h}$ of incubation at $4{ }^{\circ} \mathrm{C}$, using Trolox (6-hydroxy-2,5,7,8-tetramethylchroman-2-carboxylic acid) as standard. The antioxidant capacity was expressed as $\mu \mathrm{mol}$ Trolox equivalents for $\mathrm{mg}$ of sample fresh weight (FW).

\section{Statistical analysis}

Basic statistics for morphological parameters: number of stomata, the stomata area $\left(\mu \mathrm{m}^{2}\right)$, and the total stomata surface (mean number of stomata found on a surface of $0.8 \mathrm{~mm}^{2} \times$ 
mean stomata area, $\mu \mathrm{m}^{2}$ ) were calculated and performed in Excel.

Statistically significant differences among treatments were analyzed by one-way analysis of variance (ANOVA). Shapiro-Wilk and Kolmogorov-Smirnov tests were performed to check for normality. The Holm-Sidak and Tukey's tests were applied for all multiple comparison procedures based on a significance level of $p<0.05$, for physiological and morphological parameters, respectively. The package Sigma-Plot 11.0 (Jandel Scientific, San Rafael, CA, USA) was used for statistical data processing.

\section{Results and discussion}

\section{Responses on stomata}

Results of stomata counting and stomata area calculation are reported in Table 1 and Fig. 1. The stomata number varied significantly depending on cultivar: control plants of Sardo cv. had the highest number of stomata for each surface unit (on average 213), almost twice the number of stomata counted in Spagnolo (on average 117, Fig. 1c). In both cardoon Sardo and Siciliano, metal treatments significantly decreased the stomata number. Moreover, alterations in stomata shape were occasionally observed in the latter (Fig. 1s-supplementary). A decrease in the stomata number was already observed in Beta vulgaris in response to an excess of the micronutrient $\mathrm{Zn}$ (Sagardoy et al. 2010).

By contrast, in Spagnolo cv. grown under metal stress, the number of stomata significantly increased, especially with $\mathrm{Cd}$, where stomata nearly doubled those of control plants. In addition, in Sardo and Siciliano cultivars, a noticeable increase of the stomata area was also observed (significant in Sardo treated with $\mathrm{Cd}$ ). This result can be interpreted as a compensative response of the plants under metal stress, to counteract the decrease of the stomata number.

However, this response seems not enough to cope with the reduced number of stomata; in fact, only in the case of $\mathrm{Pb}$ treated plants of Sardo, a complete recovery of the total stomata surface was achieved. In Spagnolo cardoon, the sole increase of the stomata number produced a parallel increase of the total stomata surface, with positive effect on gas exchange.

An increase of the stomata number in plants grown under the metal presence was already observed in the literature; in wheat seedlings grown with $\mathrm{Cu}$ and $\mathrm{Zn}$, the number of stomata increased with a dose-dependent trend (Stolarska et al. 2007). In soybean seedlings grown in the presence of $\mathrm{Pb}$, an increase of the stomata number coupled to a reduction in their size was observed (Weryszko-Chmielewska and Chwil 2005). In the latter case, the authors suggested that a larger number of epidermal cells enhance detoxification mechanisms. Given that several papers report the negative effects of heavy metals on plant metabolic pathways, stomata which are more numerous but reduced in size could provide a prompt response in gas exchange. This could explain why in cardoon, where stomata undergo a double regulation pattern under metal stress (i.e., in number and size), the stomata number is more important than size for gas exchanges and photosynthesis.

\section{Responses on roots: morphology, element uptake, and translocation}

The observation of root apparatus after $30 \mathrm{~d}$ of culture (Fig. 2) highlighted the presence of 3-6 roots, similarly developed in control and metal-treated plants; however, the observation of the root tip under a light microscope evidenced the absence of root hairs in control plants, and the development of numerous root hairs in metal-treated plants, especially with $\mathrm{Pb}$, where the hairy zone was about twice that of Cd-treated plants (7-
Table 1 Stomata number and area in control and metal-treated cultivars of $C$. cardunculus

\begin{tabular}{lllll}
\hline $\mathrm{Cv}$ & Treatment & Stomata number ${ }^{\S}(\mathrm{N})$. & Stomata area $\left(\mu \mathrm{m}^{2}\right)$ & Total stomata surface $^{\S}\left(\mu \mathrm{m}^{2}\right)$ \\
\hline \multirow{4}{*}{ Sardo } & ${ }^{*} \mathrm{C}$ & Mean $\pm \mathrm{SD}$ & Mean $\pm \mathrm{SD}$ & Mean $\pm \mathrm{SD}$ \\
& $\mathrm{Cd}$ & $213 \pm 19^{\mathrm{ab}}$ & $383 \pm 50^{\mathrm{c}}$ & $79921 \pm 13794^{\mathrm{ab}}$ \\
& $\mathrm{Pb}$ & $152 \pm 28^{\mathrm{cd}}$ & $531 \pm 84^{\mathrm{ab}}$ & $51177 \pm 14022^{\mathrm{b}}$ \\
Siciliano & $\mathrm{C}$ & $145 \pm 67^{\mathrm{cd}}$ & $340 \pm 73^{\mathrm{c}}$ & $80541 \pm 37958^{\mathrm{ab}}$ \\
& $\mathrm{Cd}$ & $170 \pm 33^{\mathrm{bc}}$ & $466 \pm 125^{\mathrm{ab}}$ & $80213 \pm 29975^{\mathrm{ab}}$ \\
& $\mathrm{Pb}$ & $100 \pm 7^{\mathrm{d}}$ & $506 \pm 127^{\mathrm{ab}}$ & $62809 \pm 18004^{\mathrm{ab}}$ \\
Spagnolo & $\mathrm{C}$ & $117 \pm 7^{\mathrm{d}}$ & $583 \pm 96^{\mathrm{a}}$ & $47056 \pm 6268^{\mathrm{b}}$ \\
& $\mathrm{Cd}$ & $231 \pm 42^{\mathrm{a}}$ & $463 \pm 86^{\mathrm{abc}}$ & $54372 \pm 12585^{\mathrm{b}}$ \\
& $\mathrm{Pb}$ & $168 \pm 51^{\mathrm{bc}}$ & $447 \pm 46^{\mathrm{bc}}$ & $92265 \pm 25328^{\mathrm{a}}$ \\
& & $385 \pm 60^{\mathrm{c}}$ & $71502 \pm 26932^{\mathrm{ab}}$ \\
\hline
\end{tabular}

${ }^{*} C$ control, $S D$ standard deviation. Different letters indicate significant differences $(p<0.05)$ among the treatments according to Tukey's post hoc test. ${ }^{\S}$ All parameters were estimated on a surface of $0.8 \mathrm{~mm}^{2}$ 
Fig. 2 Roots of control plants of Spagnolo (a, b), Siciliano (c), and Sardo (d) cardoon cultivars. Roots of Cd-treated plants of Sardo,

Siciliano, and Spagnolo (e, f, and $\mathrm{g}$, respectively). Roots of $\mathrm{Pb}$ treated plants of Sardo, Siciliano, and Spagnolo $(\mathrm{h}-\mathrm{j})$. See paragraph 3.2 for details

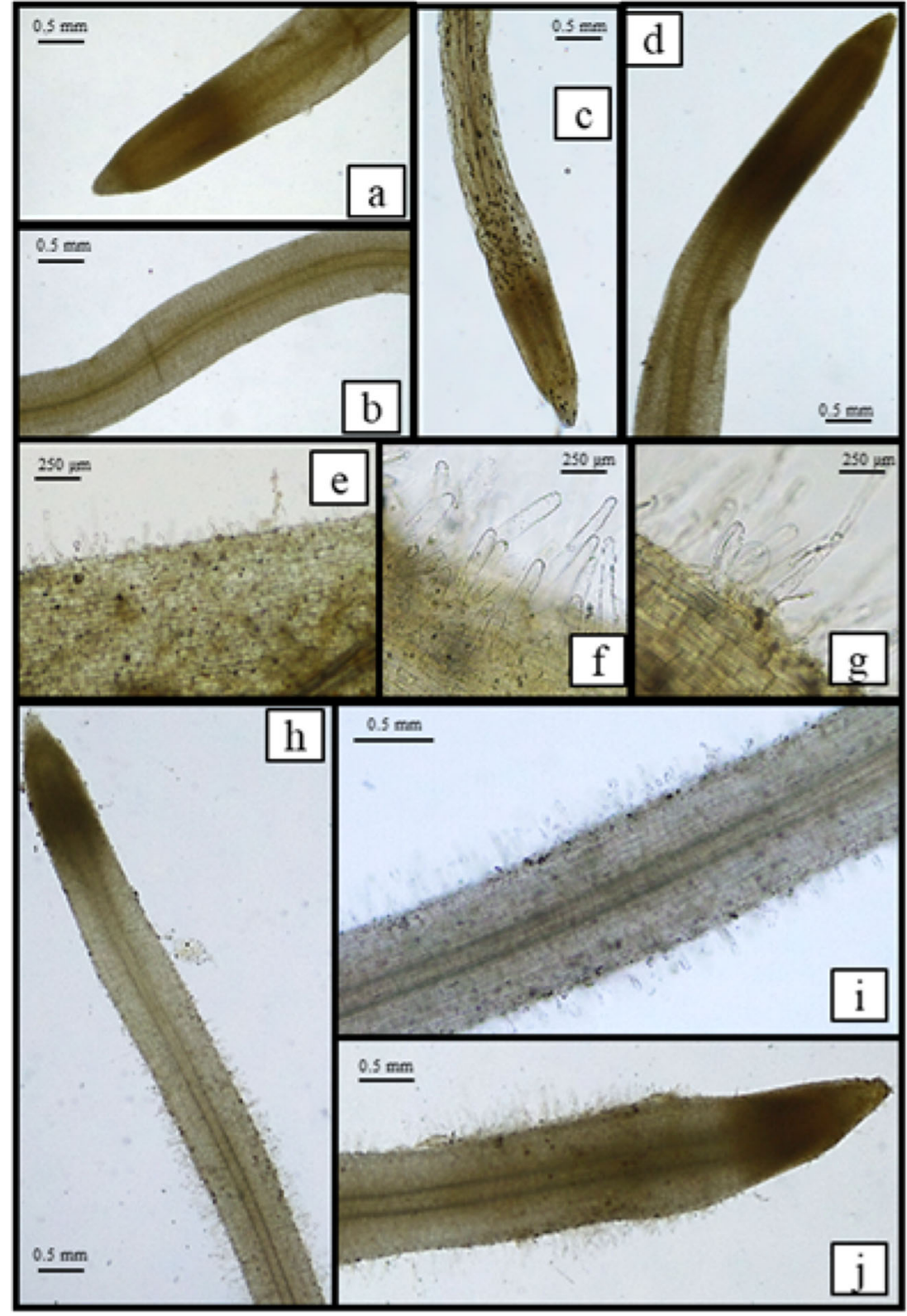

$8 \mathrm{~mm}$ vs. 3-4). The presence of root hairs could be interpreted as a plant response to metal stress, overall enhancing the root surface, cell wall binding sites for cations, and likely element absorption/adsorption and sequestration in the walls (Krzesłowska 2011; Parrotta et al. 2015).

Cadmium and $\mathrm{Pb}$ concentrations and their translocation factors (TF) in plants are reported in Table 2. Element concentrations were below the detection limit (BDL) in control plants. Significant differences were observed between different organs (i.e., root vs. leaves) and between EDTA-treated and untreated leaves. The EDTA washing demonstrates that a conspicuous part of $\mathrm{Cd}$ and $\mathrm{Pb}$ does not belong to the extracellular soluble fraction (removed by EDTA) but is likely located inside the cells. This could explain the noticeable physiological and ultrastructural alterations observed in a previous work in which cardoon plants were cultured under metal stress in industrial soil (Sorrentino et al. 2018). By contrast, no significant difference was observed between cultivars; these results agree with previous findings, showing that the same three cultivars did not display significant differences in their element uptake when grown on industrial soil (Capozzi et al. 2020). Moreover, in the present experiment, $\mathrm{Cd}$ and $\mathrm{Pb}$ concentrations in shoot and root resulted higher than those measured in a previous experiment carried out on gardening soil watered with metal solutions (Arena et al. $2017 \mathrm{a}, \mathrm{b})$, at parity of metal concentration $\left(10^{-5} \mathrm{M}\right)$ and growth period $(30 \mathrm{~d})$. This result is consistent in the two cases reflecting the amounts of metals received; in fact, the plants grown in gardening soil received about $600 \mathrm{~mL}$ metal solution each, whereas in hydroponics, every plant received about 1.5 
Table 2 Element concentrations (ppm on dry weight, mean $\pm \mathrm{SD}, n=5$ ) in leaf ( $\mathrm{L}$ and $\mathrm{L}+\mathrm{EDTA}$ ), $\operatorname{root}(\mathrm{R})$, and relative translocation factor $(\mathrm{TF})$ in the three cardoon cultivars

\begin{tabular}{llll}
\hline & Sardo & Siciliano & Spagnolo \\
\hline $\mathrm{Cd}$ & & & \\
$\mathrm{L}$ & $183 \pm 17^{\mathrm{b}}$ & $152 \pm 19^{\mathrm{b}}$ & $184 \pm 81^{\mathrm{b}}$ \\
$\mathrm{L}+$ & $138 \pm 10^{\mathrm{c}}$ & $102 \pm 14^{\mathrm{c}}$ & $146 \pm 62^{\mathrm{c}}$ \\
$\quad$ EDTA & $693 \pm 53^{\mathrm{a}}$ & $573 \pm 59^{\mathrm{a}}$ & $642 \pm 75^{\mathrm{a}}$ \\
$\mathrm{R}$ & 0.26 & 0.26 & 0.29 \\
$\mathrm{TF}$ & & & \\
$\mathrm{Pb}$ & $63 \pm 13^{\mathrm{b}}$ & $48 \pm 11^{\mathrm{b}}$ & $57 \pm 8^{\mathrm{b}}$ \\
$\mathrm{L}$ & $47 \pm 14^{\mathrm{c}}$ & $29 \pm 6^{\mathrm{c}}$ & $31 \pm 12^{\mathrm{c}}$ \\
$\mathrm{L}+$ & 824 & $891 \pm 31^{\mathrm{a}}$ & 1110 \\
$\mathrm{EDTA}$ & $\pm 102^{\mathrm{a}}$ & & $\pm 182^{\mathrm{a}}$ \\
$\mathrm{R}$ & 0.06 & 0.05 & 0.05 \\
$\mathrm{TF}$ & & &
\end{tabular}

$\mathrm{L}$ metal solution $\left(10^{-5} \mathrm{M}\right)$ in $30 \mathrm{~d}$. In addition, the metals in solution could become partly inaccessible when supplied to the soil by irrigation; soil is indeed a complex matrix able to bind temporarily or stably metal ions, whereas they could preserve their bioavailability in hydroponics. Further, comparing the two experiments (gardening soil vs. hydroponics), in the first, translocation factors of $199 \%$ and $74 \%$ were calculated for $\mathrm{Cd}$ and $\mathrm{Pb}$, values far long higher than those calculated in hydroponics (26-29\% for $\mathrm{Cd}$ and 5-6\% for $\mathrm{Pb}$ ). All the same, it confirmed the higher value of TF for $\mathrm{Cd}$. It is reported, indeed, that plant nutrients and $\mathrm{Cd}$ compete for the same transporters; therefore, $\mathrm{Cd}$ can be easily absorbed and translocated to the shoot (Nazar et al. 2012). This discrepancy could be due to the presence of root hairs, which develop only in metal-treated plants grown in hydroponics; root hairs could indeed provide a large surface for metal sequestration. The lack of root hairs in hydroponic control can be considered as an expected trait; in fact, root hairs develop to increase the root surface ensuring an adequate water supply, even in very small spaces, as between soil particles. The development of root hairs in $\mathrm{Cd}$ - and $\mathrm{Pb}$-contaminated hydroponics could be a response to metal stress and especially to $\mathrm{Pb}$, since the hairy zone was particularly developed in these plants and was coupled to a very low TF to the shoot.

Different letters indicate statistical differences according to Tukey's post hoc test $(p<0.05)$

\section{Gas exchanges}

Leaf gas-exchange measurements are reported in Fig. 3. It is evident how Sardo and Siciliano cardoon showed the same trend of response in the measurements, being higher in control plants and lower in $\mathrm{Cd}$ and $\mathrm{Pb}$, whereas Spagnolo showed a different physiological behavior, with no difference in net

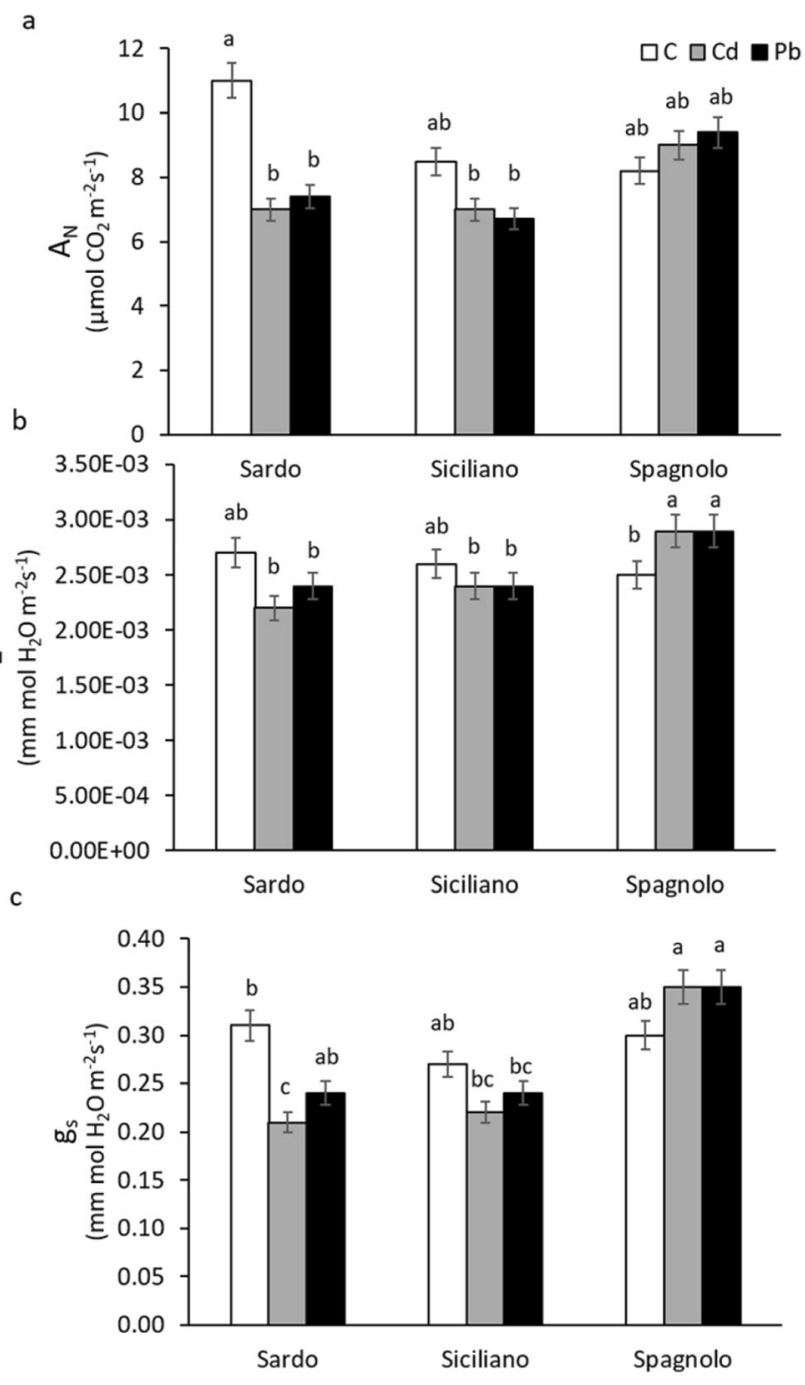

Fig. 3 Net photosynthesis $\left(A_{N}\right)$ (a), transpiration rate $(E)(\mathrm{b})$, and stomatal conductance $\left(g_{s}\right)(\mathrm{c})$ measured on control $(\mathrm{C})$, Cd-treated, and Pb-treated Sardo, Siciliano, and Spagnolo cultivar. Data are the mean $\pm \mathrm{SD}, n=5$. Different letters indicate significant differences among the treatments, according to Tukey's post hoc test $(p<0.05)$

photosynthesis among control and treated plants (Fig. 3a) and a significant increase of transpiration and stomatal conductance in polluted plants (Fig. 3b, c). More specifically, Sardo presented the highest net photosynthesis and stomata conductance in nonpolluted plants, values which significantly decreased in $\mathrm{Cd}$ - and $\mathrm{Pb}$-contaminated plants (Fig. 3a, b). These data were in agreement with those of the stomatal counting. Indeed, the highest presence of stomata could allow a higher stomata conductance, which in turn accounted for enhanced photosynthesis. Conversely, in Spagnolo grown under metal stress, there was an increase in both transpiration and stomatal conductance compared to control (Fig. 3b, c). Once again, these data agree with stomatal counting, where Spagnolo grown in the presence of $\mathrm{Pb}$ and $\mathrm{Cd}$ increased the stomata number. Indeed, gas exchanges in leaves are recognized to be controlled by several anatomical traits (i.e., 
stomatal number, size, and aperture), affecting the stomatal conductance and the diffusion through the mesophyll (Haworth et al. 2016; Xiong et al. 2017). From our results, it is also worth mentioning that $\mathrm{Cd}$ reduced stomata conductance and evapotranspiration more than $\mathrm{Pb}$ in the cultivars Sardo and Siciliano (Fig. 3).

\section{Photosynthetic pigment content}

Photosynthetic pigment content represents a suitable proxy for the detection of damages to photosynthetic apparatus. In our experiment, Spagnolo and Sardo showed a higher content of photosynthetic pigments (Fig. 4) in control and $\mathrm{Pb}$ plants, differently from Siciliano cultivar in which the pigment amount was significantly reduced under $\mathrm{Cd}$ and $\mathrm{Pb}$ treatments compared to control.

These results indicate a higher sensitivity to $\mathrm{Cd}$, compared to $\mathrm{Pb}$, in Spagnolo and Sardo cardoon, and an overall vulnerability of Siciliano cultivar to both metals regards pigments. The reduction of chlorophylls and carotenoids due to heavy metal contamination has often been reported as a damage occurring at the enzymatic level during the chlorophyll synthesis or by inducing oxidative stress that results harmful for

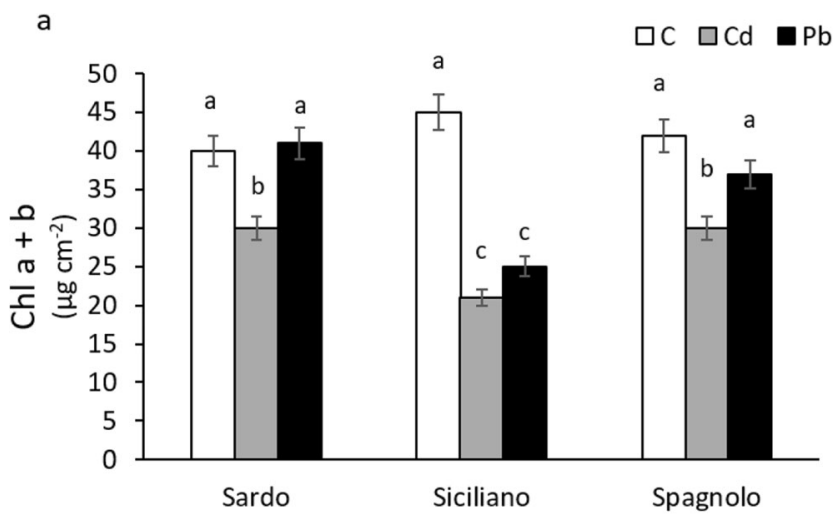

b

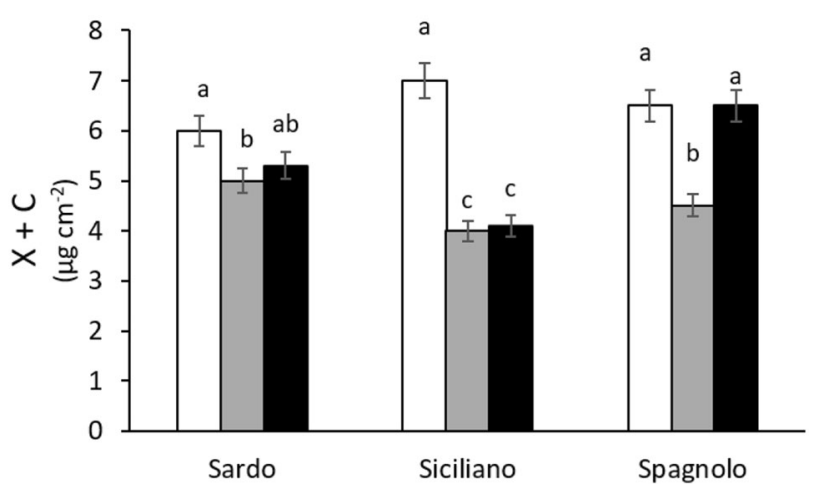

Fig. 4 Total chlorophylls $(\mathrm{Chl} \mathrm{a}+\mathrm{b})(\mathrm{a})$, total carotenoids $(\mathrm{x}+\mathrm{c})(\mathrm{b})$ determined on control (C), Cd-treated, and Pb-treated Sardo, Siciliano, and Spagnolo cultivar. Data are the mean $\pm \mathrm{SD}, n=5$. Different letters indicate significant differences among the treatments, according to Tukey's post hoc test $(p<0.05)$ the biosynthetic pathways of photosynthetic pigments (Prajapati and Tripathi 2008; De Micco et al. 2019). One of the most common results of injuries by heavy metal contamination is chlorosis. Metals interfere with pigment and influence the $\mathrm{Chl}$ content in plants as $\mathrm{Mg}^{2+}$ in chlorophyll is substituted by $\mathrm{Cu}^{2+}, \mathrm{Zn}^{2+}, \mathrm{Cd}^{2+}, \mathrm{Hg}^{2+}, \mathrm{Pb}^{2+}$, or $\mathrm{Ni}^{2+}$ (Küpper et al. 1996). In our study, pigment content was significatively affected by heavy metals in Siciliano plants (Fig. 4) with repercussion on net photosynthesis (Fig. 3a).

Various authors have reported similar decreases in pigment content under heavy metal stress (Zengin and Munzuroglu 2006; Arena et al. 2014), whereas only a few have found enhanced concentrations of photosynthetic pigments after the exposure to metals (Devi Prasad and Devi Prasad 1982). These contradictory results are probably due to the effects of mixed heavy metals on the soil water medium, which compete with each other. Furthermore, in Sardo and Spagnolo, both chlorophyll and carotenoids decreased when treated with $\mathrm{Cd}$ but not with $\mathrm{Pb}$. A significant inhibitory effect on photosynthetic pigments was found in our previous study with cardoon plants grown on polluted soil and was ascribed to the major presence of Cd (Sorrentino et al. 2018). This result confirms that cadmium is harmful to pigments probably because of its fast delivery through plants and accumulation in leaves compared to other heavy metals (Nwosu et al. 1995; John et al. 2009).

\section{Fluorescence emission measurements}

$\mathrm{Cd}$ and $\mathrm{Pb}$ exert different effects on the diverse components of photosynthetic apparatus; $\mathrm{Cd}$ seems to be more deleterious than $\mathrm{Pb}$ on light-harvesting pigments, but photosystem efficiency is more affected by $\mathrm{Pb}$, even if the outcomes depend on intrinsic sensitivity of the different cardoon cultivars. The chlorophyll $a$ fluorescence emission analyses showed that the quantum yield of PSII electron transport ( $\phi$ PSII), the electron transport rate (ETR), and the maximum PSII photochemical efficiency $\left(F_{v} / F_{m}\right)$ were negatively affected only by $\mathrm{Pb}$, in Sardo and Siciliano cultivars. Conversely, no effect following both metal treatments was detected in Spagnolo, confirming the highest capability of this cultivar to face the metal stress (Fig. 5a-c). The nonphotochemical quenching (NPQ) significantly rose under $\mathrm{Pb}$ treatment, in all cultivars, compared to $\mathrm{Cd}$ and control, indicating that under Cd treatment, photosynthetic apparatus promoted the thermal dissipation of energy not utilized in photochemistry (Fig. 5d) (Arena et al. 2017a, b). The higher photochemical efficiency of Spagnolo, compared to Sardo and Siciliano, was in accordance with the highest net photosynthetic rates measured in this cultivar under $\mathrm{Cd}$ and $\mathrm{Pb}$ treatments. From our data, it is evident that for the cultivars Sardo and Siciliano, the gas exchanges were more responsive than PSII photochemistry to metal stress, because the treatment with both $\mathrm{Cd}$ and $\mathrm{Pb}$ determined a significant reduction of net photosynthesis, together with a 
a

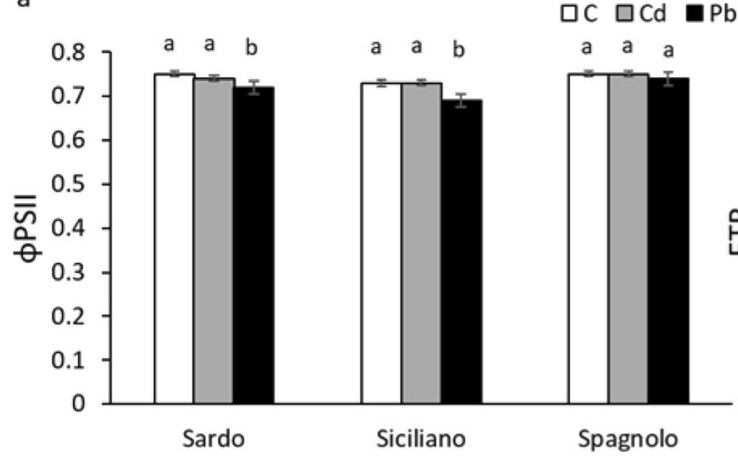

c

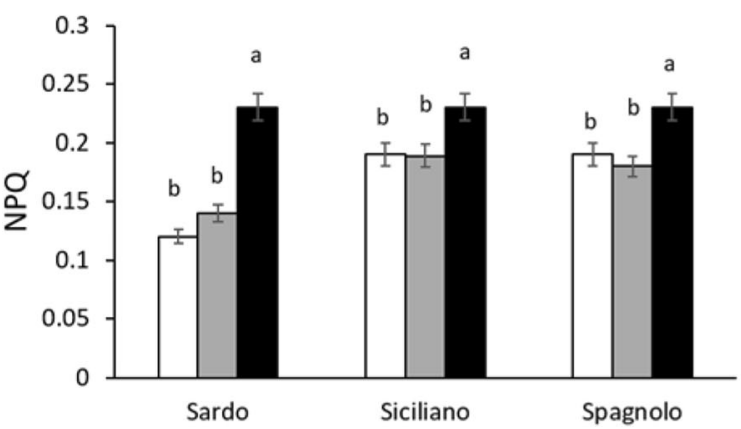

Fig. 5 Quantum yield of PSII electron transport (ФPSII) (a), electron transport rate (ETR) (b) nonphotochemical quenching (NPQ) (c), PSII maximum quantum yield $\left(F_{v} / F_{m}\right)$, measured on control $(\mathrm{C})$, Cd-treated,

decline of stomatal number and photosynthetic pigment content. We suggest that the higher resistance of Spagnolo cultivar to $\mathrm{Cd}$ and $\mathrm{Pb}$ depends on an elevated capability to harvest and convert light in photochemistry, also in addition to a strong stomatal regulation allowing plants to carry out a fine-tuning of light and dark processes of photosynthesis.

\section{Antioxidant response}

The three cultivars showed a different antioxidant power both in control plants and in response to metal injuries (Fig. 2s). It has been demonstrated that in natural ecosystems, the plant antioxidant production depends on several factors such as climate, soil, geographic location where plants grow, and, of course, species (George et al. 2004; Lebasky and Sharifi Ashoorabadi 2001; Ogaya et al. 2011); this could explain the different antioxidant power observed in the three cultivars also in the control condition. Particularly, the significantly lower value $(p<0.01)$ of antioxidant capacity in Spagnolo control plants compared to Sardo and Siciliano could indicate a reduced need to develop a strong antioxidant system in this cultivar due to its intrinsic capacity to withstand metal stress.

Whereas in Sardo, no variation in antioxidant capacity among control and treated plants was found; in Siciliano Cd- and Pbtreated plants, this parameter significantly decreased compared to control, indicating a negligible role of the antioxidants under heavy metal stress in this cultivar (Fig. 2s). In addition, the b

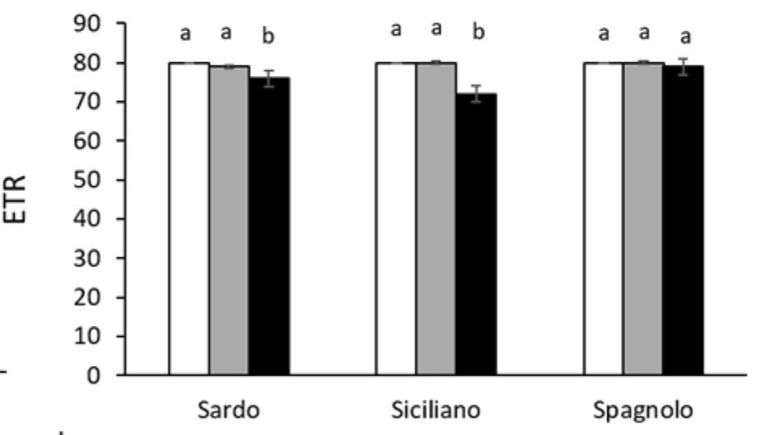

d

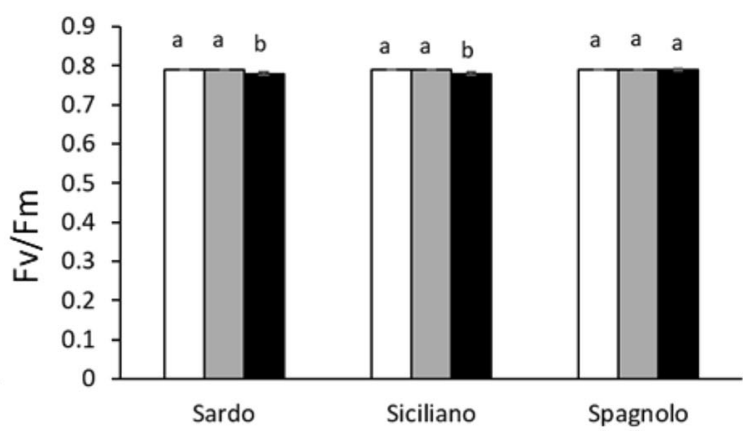

and $\mathrm{Pb}$-treated Sardo, Siciliano, and Spagnolo cultivar. Data are the mean $\pm \mathrm{SD}, n=5$. Different letters indicate significant differences among the treatments, according to Tukey's post hoc test $(p<0.05)$

Siciliano cultivar, although the higher constitutive antioxidant capacity, is not able to face the injuries under metal stress, as demonstrated by the sporadic occurrence of damaged stomata (Fig. 1s) and chloroplasts (Sorrentino et al. 2018).

Conversely, compared to control, Spagnolo cultivar showed a significant increase of antioxidant capacity in Cd- and even more in Pb-treated plants (Fig. 2s), suggesting a remarkable contribution of antioxidant compounds in plant defense against $\mathrm{Cd}$ and $\mathrm{Pb}$ injuries. Our results indicate that heavy metal stress influences antioxidant status, providing three cultivar-specific responses. However, as the FRAP assay only measures nonenzymatic (reductants) antioxidants in plant samples, we cannot exclude the occurrence of other effects involving specific enzymatic pathways, such as superoxide dismutase (SOD) or catalase (CAT) (Gjorgieva et al. 2013).

\section{Conclusions}

This work clarifies several strategies of cardoon plants to cope with metal stress. Primarily, the modulation of the number and size of the stomata is proposed as a proxy for evaluating the tolerance to metals by potential phytoremediation plants. In fact, the increase of stomata of reduced size enhances gas exchange ability, determining the growth of healthy plants.

Some results indicate that Cynara cardunculus plants display and face metal injuries by active morphophysiological 
changes, regardless of the cultivar; specifically, root hair development and pigment content decrease. Other traits show instead a cultivar-specific behavior; particularly, photosynthetic pattern and stomata plasticity provide different responses, but only Spagnolo cardoon achieves a successful strategy preserving its morphophysiology. The stomata response follows two different patterns: the increase of the stomata area (i.e., Sardo and Siciliano) and the increase of the stomata number (i.e., Spagnolo). Only, this latter leads to a real resilience to metal stress, by improving the photosynthetic performance both in terms of $\mathrm{CO}_{2}$ absorption and light harvesting and conversion to photosystems. It is likely that the entrance of $\mathrm{Cd}$ and $\mathrm{Pb}$ into the cells, proved by the chemical analysis, induces a decrease in pigment concentration, which may be the first signal of an impending decline in net photosynthesis. This event, in turn, determines the onset of recovery mechanisms at the stomata level and adjustments in the photochemistry in Spagnolo cardoon. The increase of antioxidant capacity and the ability of Spagnolo plants to modify leaf structural and physiological traits under heavy metal contamination to maintain high photosynthetic efficiency should be considered an elective trait for its cultivation in polluted environments.

Supplementary Information The online version contains supplementary material available at https://doi.org/10.1007/s11356-021-13242-9.

Acknowledgements We wish to thank Dr. Riccardo Riccardi (Arca 2010 scarl) for providing us C. cardunculus seeds.

Availability of data and materials All data supporting the results are included in the manuscript.

Author contribution Conceptualization of the experiment: Valeria Spagnuolo and Simonetta Giordano; investigation: Maria Cristina Sorrentino, Fiore Capozzi, Chiara Amitrano, and Gaetano De Tommaso; data curation: Valeria Spagnuolo, Carmen Arena, Maria Cristina Sorrentino, and Mauro Iuliano; statistical analysis: Fiore Capozzi and Chiara Amitrano; writing (original draft preparation): Valeria Spagnuolo, Maria Cristina Sorrentino, and Carmen Arena; writing (review and editing): all the authors; supervision: Valeria Spagnuolo.

Funding Open access funding provided by Università degli Studi di Napoli Federico II within the CRUI-CARE Agreement.

\section{Declarations}

Ethics approval This study does not involve human participants.

Consent to participate This study does not involve human participants nor human data or human tissue.

Consent to publish This manuscript does not contain individual person's data.

Conflict of interest The authors declare no conflict of interest and no financial and nonfinancial competing interests.
Open Access This article is licensed under a Creative Commons Attribution 4.0 International License, which permits use, sharing, adaptation, distribution and reproduction in any medium or format, as long as you give appropriate credit to the original author(s) and the source, provide a link to the Creative Commons licence, and indicate if changes were made. The images or other third party material in this article are included in the article's Creative Commons licence, unless indicated otherwise in a credit line to the material. If material is not included in the article's Creative Commons licence and your intended use is not permitted by statutory regulation or exceeds the permitted use, you will need to obtain permission directly from the copyright holder. To view a copy of this licence, visit http://creativecommons.org/licenses/by/4.0/.

\section{References}

Angelone M, Bini C (1992) Trace elements concentrations in soils and plants of Western Europe. In: Biogeochemistry of trace metals. Lewis publishers, Boca Raton, pp 19-60

Arena C, De Maio A, De Nicola F, Santorufo L, Vitale L, Maisto G (2014) Assessment of eco-physiological performance of Quercus ilex L. leaves in urban area by an integrated approach. Water Air Soil Pollut:225-1824. https://doi.org/10.1007/s11270-013-1824-6

Arena C, Santorufo L, Cataletto PR, Memoli V, Scudiero R, Maisto G (2017a) Eco-physiological and antioxidant responses of holm oak (Quercus ilex L.) leaves to Cd and Pb. Water Air Soil Pollut:228459. https://doi.org/10.1007/s11270-017-3638-4

Arena C, Figlioli F, Sorrentino MC, Izzo LG, Capozzi F, Giordano S, Spagnuolo V (2017b) Ultrastructural, protein and photosynthetic alteration induced by $\mathrm{Pb}$ and $\mathrm{Cd}$ in Cynara cardunculus L. and its potential for phytoremediation. Ecotox Environ Safe 145:83-89. https://doi.org/10.1016/j.ecoenv.2017.07.015

Bilger W, Björkman O (1990) Role of xanthophyll cycle and energy dissipation in differently oriented faces of light-induced absorbance changes, fluorescence and photosynthesis in Hedera canariensis. Photosynth Res 25:173-185

Branquinho C, Brown DH (1994) A method for studying the cellular location of lead in lichens. Lichenologist 26:83-90

Branquinho C, Brown DH, Catarino F (1997) The cellular location of Cu in lichens and its effects on membrane integrity and chlorophyll fluorescence. Environ Exp Bot 38:165-179. https://doi.org/10. 1016/S0098-8472(97)00015-4

Capozzi F, Sorrentino MC, Caporale AG, Fiorentino N, Giordano S, Spagnuolo V (2020) Exploring the phytoremediation potential of Cynara cardunculus: a trial on an industrial soil highly contaminated by heavy metals. Environ Sci Pollut Res 27:9075-9084. https://doi. org/10.1007/s11356-019-07575-9

Chandra R, Kang H (2016) Mixed heavy metal stress on photosynthesis, transpiration rate, and chlorophyll content in poplar hybrids. Forest Sci Technol 12:55-61. https://doi.org/10.1080/21580103.2015.1044024

Chaney RL (2015) How does contamination of rice soils with Cd and Zn cause high incidence of human $\mathrm{Cd}$ disease in subsistence rice farmers. Curr Pollut Rep 1:13-22. https://doi.org/10.1007/s40726-015-0002-4

Costanzo G, Iesce MR, Naviglio D, Ciaravolo M, Vitale E, Arena C (2020) Comparative studies on different Citrus cultivars: a revaluation of waste mandarin components. Antioxidants 517:1-12. https:// doi.org/10.3390/antiox 9060517

De Micco V, Amitrano C, Stinca A, Izzo LG, Zalloni E, Balzano A, Barile R, Conti P, Arena C (2019) Dust accumulation due to anthropogenic impact induces anatomical and photochemical changes in leaves of Centranthus ruber growing on the slope of the Vesuvius volcano. Plant Biol 22:93-102. https://doi.org/10.1111/plb.12966

Devi Prasad PV, Devi Prasad PS (1982) Effects of cadmium, lead and nickel on three freshwater green algae. Water Air Soil Pollut 17:263-268 
Figlioli F, Sorrentino MC, Memoli V, Arena C, Maisto G, Giordano S, Capozzi F, Spagnuolo V (2019) Overall plant responses to Cd and $\mathrm{Pb}$ metal stress in maize: Growth pattern, ultrastructure, and photosynthetic activity. Environ Sci Pollut Res 26:1781-1790

Genty B, Briantais JM, Baker NR (1989) The relationship between the quantum yield of photosynthetic electron transport and quenching of chlorophyll fluorescence. Biochim Biophys Acta 90:87-92

George B, Kaur C, Khurdiya DS, Kapoor HC (2004) Antioxidants in tomato (Lycopersicum esculentum) as a function of genotype. Food Chem 84:45-51

Gjorgieva D, Panovska TK, Ruskovska T, Bačeva K, Stafilov T (2013) Influence of heavy metal stress on antioxidant status and DNA damage in Urtica dioica. Biomed Res Int 2013:1-6. https://doi.org/10. $1155 / 2013 / 276417$

Haworth M, Killi D, Materassi A, Raschi A and Centritto M (2016) Impaired Stomatal Control Is Associated with Reduced Photosynthetic Physiology inCrop Species Grown at Elevated [CO2]. Front Plant Sci 7:1568. https://doi.org/10.3389/fpls.2016.01568

He Z, Shentu J, Yang X, Baligar VC, Zhang T, Stoffella PJ (2015) Heavy metal contamination of soils: sources, indicators, and assessment. J Environ Ind 9:17-18

Hoagland DR, Arnon DI (1950) The water culture method for growing plants without soil. Col Agric Exp Stn Circ 347:1-32

John R, Ahmad P, Gadgil K, Sharma S (2009) Heavy metal toxicity: effect on plant growth, biochemical parameters and metal accumulation by Brassica juncea L. Int J Plant Prod 3:65-75

Kitajima M, Butler WL (1975) Quenching of chlorophyll fluorescence and primary photochemistry in chloroplasts by dibromothymoquinone. Biochim Biophys Acta 376(1):105-115

Krall JP, Edwards GE (1992) Relationship between photosystem II activity and CO2 fixation in leaves. Physiol Plant 86(1):180-187

Krupa Z, Baszyński T (1995) Some aspects of heavy metals toxicity towards photosynthetic apparatus - direct and indirect effects on light and dark reactions. Acta Physiol Plant 17:177-190

Krzesłowska M (2011) The cell wall in plant cell response to trace metals: polysaccharide remodeling and its role in defense strategy. Acta Physiol Plant 33:35-51. https://doi.org/10.1007/s11738-010-0581-Z

Küpper H, Küpper F, Spiller M (1996) Environmental relevance of heavy metal-substituted chlorophyll using the example of water plants. J Exp Bot 47:259-266

Lebasky MJ, Sharifi Ashoorabadi A (2001) Changes in Hypericin in different habitats of Goli. Research of Iranian medicinal plants and herbs. Res Inst Fore Rang 11:100-187

Lichtenthaler HK (1987) Chlorophylls and carotenoids, pigments of photosynthetic biomembranes. Methods Enzymol 148:350-382

Markert B (1993) Plants as biomonitors: indicators for heavy metals in the terrestrial environment. VCH Publishers, New York $644 \mathrm{p}$. ISBN 3-52-73000-15

Meggeson TP, Hall NW (1999) An investigation into the spatial and temporal distribution of lead, cadmium and zinc in contemporary soils and paleosols in a high arctic and an arctic alpine environment. In: Abstracts of 'European Perspectives on Land Contamination Conference' Soc. of the Chem. Ind., London. Land Contamination and Reclamation 7(4).

Molas J (2002) Changes of chloroplast ultrastructure and total chlorophyll concentration in cabbage leaves caused by excess of organic Ni(II) complexes. Environ Exp Bot 47:115-126. https://doi.org/10. 1016/S0098-8472(01)00116-2

Motuzova GV, Minkina TM, Karpova EA, Barsova NU, Mandzhieva SS (2014) Soil contamination with heavy metals as a potential and real risk to the environment. J Geochem Explor 144:241-246

Myśliwa-Kurdziel B, Prasad MNV, Strzalka K (2002) Heavy metal influence on the light phase of photosynthesis. Physiology and biochemistry of metal toxicity and tolerance in plants. Dordrecht Kluwer Academic Publishers (pg. 229-255).
Nazar R, Iqbal N, Masood A, Iqbal Khan RM, Syeed S, Khan N (2012) Cadmium toxicity in plants and role of mineral nutrients in its alleviation. Am J Plant Sci 3:1476-1489. https://doi.org/10.4236/ajps.2012.310178

Nriagu JO (1978) The biogeochemistry of lead in the environment. Elsevier, Amsterdam, pp 18-88

Nwosu JU, Harding AK, Linder G (1995) Cadmium and lead uptake by edible crops grown in a silt loam soil. Bull Environ Contam Toxicol 54:570-578

Ogaya R, Penuelas J, Asensio D, Llusia J (2011) Chlorophyll fluorescence responses to temperature and water availability in two codominant Mediterranean shrub and tree species in a long-term field experiment simulating climate change. Environ Exp Bot 73:89-93. https://doi.org/10.1016/j.envexpbot.2011.08.004

Parrotta L, Guerriero G, Sergeant K, Cai G, Hausman JF (2015) Target or barrier? The cell wall of early- and later-diverging plants vs cadmium toxicity: differences in the response mechanisms. Front Plant Sci 6:6-133. https://doi.org/10.3389/fpls.2015.00133

Prajapati SK, Tripathi BD (2008) Seasonal variation of leaf dust accumulation and pigment content in plant species exposed to urban particulates pollution. J Environ Qual 37:865-870

Prasad MNV, Strzalka K (1999) Impact of heavy metals on photosynthesis. In: Prasad MNV, Hagemeyer J (eds) Heavy metal stress in plants. Springer, Heidelberg, pp 117-138

Sagardoy R, Vázquez S, Florez-Sarasa ID, Albacete A, Ribas-Carbó M, Flexas J, Abadía J, Morales F (2010) Stomatal and mesophyll conductances to $\mathrm{CO} 2$ are the main limitations to photosynthesis in sugar beet (Beta vulgaris) plants grown with excess zinc. New Phytologist (2010) 187:145-158. https://doi.org/10.1111/j.1469-8137.2010.03241.x

Sengupta D, Marriboina S, Unnikrishnan DK, Reddy A (2019) Photosynthetic performance and sugar variations during key reproductive stages of soybean under potassium iodide-simulated terminal drought. Photosynthetica 57:458-469

Skórzyńska-Polit E, Baszyński T (1997) Differences in sensitivity of the photosynthetic apparatus in Cd-stressed runner bean plants in relation to their age. Plant Sci 128(1):11-21

Sorrentino MC, Capozzi F, Amitrano C, Giordano S, Arena C, Spanuolo V (2018) Performance of three cardoon cultivars in an industrial heavy metal-contaminated soil: effects on morphology, cytology and photosynthesis. J Hazard Mater 351:131-137

Spagnuolo V, Zampella M, Giordano S, Adamo P (2011) Cytological stress and element uptake in moss and lichen exposed in bags in urban area. Ecotoxicol Environ Saf 74:1434-1443

Stolarska A, Wrobel J, Wozniak A, Marska B (2007) Effect of zinc and copper soil contamination on the transpiration intensity and stomal index of winter crop wheat seedlings. J Elem 12:79-86

Su C, Jiang LQ, Zhang WJ (2014) A review on heavy metal contamination in the soil worldwide: situation, impact and remediation techniques. Environ Skept Crit 3:24-38

Visconti D, Fiorentino N, Stinca A, Di Mola I, Fagnano M (2018) Use of the native vascular flora for risk assessment and management of an industrial contaminated soil. Ital J Agron 13:23-33. https://doi.org/ 10.4081/ija.2018.1348

Weryszko-Chmielewska E, Chwil M (2005) Lead-induced histological and ultrastructural changes in the leaves of soybean (Glycine max (L.) Merr.). Soil Sci Plant Nutr 61:203-212

Xiong D, Douthe C, Flexas J (2017) Differential coordination of stomatal conductance, mesophyll conductance, and leaf hydraulic conductance in response to changing light across species. Plant Cell Environ 41:436-450

Zengin FK, Munzuroglu O (2006) Toxic effects of cadmium (CdCC) on metabolism of sunflower (Helianthus annuus L.) seedlings. Acta Agricult Scand Sect B 56:224-229

Publisher's note Springer Nature remains neutral with regard to jurisdictional claims in published maps and institutional affiliations. 